\title{
The Effect of Social Networks on Performance of Fresh Tomato Supply Chain in Kilolo District, Tanzania
}

\author{
Leonada Mwagike \\ School of Business, Mzumbe University, Morogoro, Tanzania
}

\author{
Email address: \\ lrmwagike@mzumbe.ac.tz
}

\section{To cite this article:}

Leonada Mwagike. The Effect of Social Networks on Performance of Fresh Tomato Supply Chain in Kilolo District, Tanzania. International Journal of Business and Economics Research. Vol. 4, No. 5, 2015, pp. 238-243. doi: 10.11648/j.ijber.20150405.12

\begin{abstract}
This paper determines the effect of social networks on performance of fresh tomato supply chain in Kilolo District Tanzania using Social Capital Theory and Transaction Cost Economic Theory. Tomato production and marketing has been identified as being important in poverty reduction mainly because it can offer employment and thus income to smallholder farmers and traders. However, smallholder farmers and traders in Kilolo District face high transaction costs in production and marketing of their produce and thus they rely on social networks to reduce transaction costs. The study employed a crosssectional research design. A simple random sampling technique was used to select smallholder tomato farmers while snow ball sampling technique was used to select tomato traders. The sample size consisted of 242 respondents. Semi-structured questionnaires were administered to the respondents. Data were analysed using means, percentages, independent samples Ttests and multiple regression analysis. The study found that membership in socio-economic groups, network size, tie strength, and network density have significant positive influence on performance of the fresh tomato supply chain in the study area. The study also found that level of education had positive influence on the performance. The main conclusion drawn from this study is that social networks have significant positive influence on performance of the fresh tomato supply chain in the study area. It is recommended that the government should recognize the importance of informal social networks and strengthen the existing social networks.
\end{abstract}

Keywords: Social Networks, Smallholder Tomato Farmers, Tomato Traders, Fresh Tomato Supply Chain, Performance, Tanzania

\section{Background and Justification}

There is a growing amount of literature that emphasizes the importance of social networks as a basis for economic activity (Fafchamps, 1996 and Anggraeni, 2009). Social networks are frequently defined in terms of the groups, networks, norms and trust that people have for productive purposes (Hualiang et al 2009; Wambungu, 2010). Social networks in tomato supply chain in Kilolo District are important for both smallholder farmers and traders, because they face high risks caused by price and production fluctuation without any formal insurance. Moreover, in remote areas, the risks are even higher because of high transportation costs, asymmetric market information and imperfections in markets for credit (Zuwarimwe and Kirsten, 2011).

Social networks are crucial to the attainment of long-term business success and have a direct impact on the market expansion and sales growth (Fafchamps, 2004). Social networks can also help to enhance marketing and negotiation and improve firm's performance (Peng and Luo, 2000; Watson, 2007). Furthermore, social networks of farmers, traders, input suppliers and group membership may reduce monitoring costs and enforcement costs associated with credit contracts on the part of the lender. According to Hualiang et al. (2009); Anggraeni (2009); Zuwarimwe and Kirsten (2011), chain actors may reduce transaction costs related to market information acquisition since it can be acquired passively during social interactions or actively from people who already know each other.

The effect of social networks on the performance of a firm is still a matter of debate. On the one hand one it has been observed that the structure of networks matters greatly. Structure is explained by the degree of redundancy and size of networks (Burt, 2000). For instance, low dense networks increase access to market information than high dense networks thereby enhancing performance. Other literature 
however, indicates that high dense networks avail more market information and capital than low dense networks (Jenssen and Greve, 2002). The other structural aspect, which has been frequently mentioned but not given adequate attention in research, is the network size (Aldrich and Zimmer 1986; Singh, 2000). In some cases it has been argued that what matters most in access to market information and capital and thereby good performance in terms of sales volume, sales revenue, market share and profits is not the strength of ties but only the size of network. While others argue that it is not only the size of networks that matters but also how diversified and effective actors are (Burt, 1992). On the other hand, the other strong view is that the content of the networks is what matters more. The content of network has sometimes been referred in terms of the strength of ties (Aldrich and Zimmer, 1986; Jensen and Greve, 2002). Accordingly, weak ties yield more resources than strong ties. The other contradictory view is that strong ties are more rewarding in terms of access to resources than weak ties (Jenssen and Greve, 2002). The argument by Burt (2000) is that what matters in the entrepreneurial activities is both intensity and content of the members of the network.

Several studies that have been undertaken in vegetable supply chain in Tanzania for example, Eaton et al., (2007); MMA (2008); SIDO (2009) and Koening at al., (2008) focused on supply chain analysis, relationship between supply chain actors, problems associated with fresh produce supply chains, factors influencing choice of marketing channels among smallholder vegetable farmers and role of institutions in vegetable supply chain in Tanzania. However, little is documented about the effect of social networks on performance of vegetable supply chain in Tanzania.

Furthermore, none of these studies quantity the effect of social networks on performance of the fresh tomato supply chain in Kilolo District, Tanzania. This paper hypothesizes that social networks have significant positive influence on the performance of the fresh tomato supply chain. The social networks indicators considered in this study included membership in socio- economic groups, network type, network size, network density and strength of ties. Other factors hypothesized to influence performance included level of education, experience in tomato business and access to market information.

\section{Methodology}

\subsection{Study Area}

This study employed a cross sectional research design. According to Bryman (2012) articulate that cross sectional research design is used so as to obtain an overall picture of what is happening in a group at a particular point in time. This study was conducted in three villages namely Madizini, Masukanzi and Lugalo in Kilolo District in Iringa Region. Iringa Region was selected because it is among the five leading regions in tomato production in Tanzania (URT, 2012). Tomato is an important cash-earning commodity for
Iringa Region. It can be estimated that 60,000 smallholder farmers are involved in tomato production in the region. According to Regional Agricultural Statistics Office, Kilolo District accounted for $51 \%$ of the 107 metric tons of tomatoes produced in the 2007/08 season while Iringa Rural District accounted for $44 \%$.

\subsection{Method of Sampling}

Unit of analysis included smallholder tomato farmers and tomato traders. A multistage sampling was used to select sample areas. The first stage involved selection of one district from Iringa Region. At this stage purposive sampling was used to select Kilolo District since it was the leading producer of tomatoes in Iringa Region. The second stage involved selection of one division from Kilolo District. Purposive sampling was used to select Mazombe division out of three divisions in the district. Mazombe division was selected because it was the leading producer of tomatoes in Kilolo District. The third stage involved selection of sample villages from Mazombe division. A random sampling technique was used to select three villages namely Madizini, Masukanzi and Lugalo. At village level a simple random sampling technique was used to select a sample of tomato producing households from the sampling frame. A total of 133 households were randomly selected from the three villages. Two wholesale markets namely Tanzania Social Action Fund and Mlamke were purposively selected out of three markets in the division. Snowball sampling technique was used to identify traders for interview who came to the wholesale markets to purchase tomatoes. The total sample size comprised of 109 traders.

\subsection{Data Sources and Methods}

Both primary and secondary data sources were used to conduct this research study. To collect primary data, semistructured questionnaire was prepared. Primary data related to tomato production, marketing and the role of social networks in production and marketing fresh tomato supply chain were gathered from the sample farmers and traders in the study area. Secondary data on the economy of Iringa Region, tomato production in the Region, previous studies on agricultural supply chain and effect of social networks on agricultural supply chain was collected from Kilolo District Agricultural Office, journals, research reports, bulletins and websites.

\subsection{Measurement of Social Networks Variables}

Social networks are most frequently defined in terms of the groups, networks, norms, and trust that people have for productive purposes. Hence the survey tool used in this study was designed to capture this multidimensionality of social networks. Six indicators of social networks were used to construct indices of social networks. Following Grootaert (1973) social networks were measured in terms of both the structural and relational dimension of social capital. Structural social capital focused on membership in social 
groups, type of networks, network size and network density of individuals and members of his or her social network. On the other hand, relational social capital focused on average strength of the ties. Social capital theory recognizes that firms in a supply chain are themselves composed of people and that the relationships among them shape the supply chain activities and outcome (Fan, 2002; Peng and Luo, 2000).

Membership in socio-economic groups was measured as a dummy variable, taking the value of 1 for actors who were members of socio-economic groups and 0 otherwise. Type of networks was measured as a dummy variable taking the value of 1 if the actor was a trader and 0 otherwise. Network size was measured as the number of individuals a farmers/trader was connected to. Network density was estimated by dividing the total number of relationships that exist between a farmer/trader with the total number of actors (Burt, 1983). Duration of relationship was measured as a dummy variable taking the value of 1 for actors who knew a contact for more than 10 years and 0 otherwise. Frequency of interaction was measured as a dummy variable taking the value of 1 when the frequency of interaction of the actor with his contacts was high and 0 otherwise. Access to market information was measured as a dummy variable with the value of 1 when the actor had ease access to market information and 0 otherwise. Level of education was measured in number of years of schooling for each actor and experience in tomato business was measured in years.

\subsection{Performance Indicators}

Two types of performance indicators namely sales volume and gross margin per tenga of tomatoes sold were used to determine the effect of social networks on performance of the fresh tomato supply chain. Sales volume as indicator of performance was measured in 'tengas' of tomatoes sold per farmer. Gross margin per tenga was used as a proxy for profitability. Gross margin is essentially the difference between the gross revenue and the variable costs and are reported in Tanzania shillings (Tshs) per tenga of tomatoes sold. (I USD=Tshs 1600-2000 for the year 2010). Smallholder farmers use a tenga in 'Kiswahili' for selling tomatoes to traders ( 1 tenga $=20$ kilogram $)$.

\subsection{Data Analysis}

Data were analysed using descriptive statistics such as mean, percentages and independent samples t-test. Independent samples-t-test was conducted to compare sales volume and gross margin per tenga of tomato sold by farmers and traders. A multiple regression model was used to determine the effect of social networks on performance of the fresh tomato supply chain. Social networks as one of the independent variables was included in the model in terms of social network variables namely membership in socio-economic groups, network type, network size, network density, duration of relationship and frequency of interaction. The independent variables were selected based on the previous studies on the effect of social networks on performance of a firm. Other factors hypothesized to influence performance are access to market information, level of education and experience in tomato business. Two separate regression models with the same explanatory variables were estimated using ordinary least squares (OLS) estimation procedure in Stata software program. The only difference was the dependent variable whereby sales volume and gross margin per tenga were the dependent variables in the first and second regression models respectively.

\section{Results and Discussion}

\subsection{The Basic Structure of the Supply Chain for Fresh Tomato}

The findings revealed that the supply chain for fresh tomato produce start right from the input, production, trade, marketing and consumption with transport as a crosssectional issue involved in several steps. The results revealed that $76 \%$ of the smallholder farmers sold their produce to middlemen (assemblers, wholesalers and retailers). Smallholder farmers opted to sell their produce to middlemen due to being geographical separated from the urban markets, poor local road network, high transportation costs and poor access to market information. This finding concurs with the finding by Mwagike and Mdoe (2015) who found that rural -urban market linkages is often provided through a network of traders. The relationships among producers, assemblers, wholesalers and retailers play an important role in the marketing of fresh tomatoes produce. Such rural-urban linkages create mutual trust among smallholder farmers and middlemen in the tomato supply chain but also cause a dependency relationship between parties.

\subsection{Volume of Tomatoes Sold by Farmers and Traders}

Table 1 compares average sales volume for the whole sample of farmers and for the whole sample of traders. As shown in Table 1, the average sales volume for traders in April-June 2010 tomato growing season was significantly $(\mathrm{P}<0.01)$ higher than that of farmers.

Table 1: Comparison of volume of tomatoes sold by farmers and traders

\begin{tabular}{llll}
\hline Actor category & \multicolumn{4}{l}{ Volume of tomatoes in tengas } \\
\hline & $\mathbf{N}$ & Mean & SD \\
\hline Farmers & 133 & 65.20 & 13.82 \\
Traders & 109 & 1002 & 1483.13 \\
Farmers Vs traders $=-\mathrm{t}=7.294 * * *, * * *$ Significant at $\mathrm{P}<0.01$ \\
\hline
\end{tabular}

\subsection{Gross Margin Obtained by Farmers and Traders}

Table 2 compares average gross margin per tenga of tomatoes sold for the whole sample of farmers and average gross per tenga of tomatoes sold for the whole sample of traders. As shown in Table 2 the mean gross per tenga of tomatoes sold by traders was significantly $(\mathrm{P}<0.01)$ higher than that of farmers. The difference in gross margins between the two groups of actors in the fresh tomato supply chain was due to difference in the volume of tomatoes handled. Traders 
handled significantly large volumes of fresh tomatoes hence achieving economies of scale leading to decrease in cost per tenga of tomatoes handled.

Table 2: Comparison of gross margin among farmers and traders

\begin{tabular}{lll}
\hline \multirow{2}{*}{ Type of chain actor } & \multicolumn{2}{l}{ Gross margin in Tshs } \\
\cline { 2 - 3 } & Mean & SD \\
\hline Farmers & 5360 & 2235.14 \\
Traders & 8610 & 5642.75 \\
\hline
\end{tabular}

Gross margin per tenga of tomatoes sold: Farmers Vs Trader- $\mathrm{t}=6.087 * * *$, $* * *$ Significant at $\mathrm{P}<0.01$

\subsection{Social Networks and Sales Volume}

Table 3 summarizes the results of the first regression model whose dependent variable was sales volume. The results in Table 3 show that five out of the nine explanatory variables hypothesized to influence sales volume was statistically significant with the hypothesized positive influence.

Table 3: Regression results of the variables that influence sales volume

\begin{tabular}{lllll}
\hline Variables $(\chi \mathbf{i})$ & Coefficient & Std. error & T-value & Significance level \\
\hline Membership in socio-economic group & 0.561 & 0.150 & 3.72 & 1.70 \\
Network type & 0.248 & 0.146 & 9.97 & $0.000^{* * *}$ \\
Network size & 0.123 & 0.012 & 0.13 & $0.000^{* * *}$ \\
Duration in relationship & 0.024 & 0.181 & 2.48 & $0.893 \mathrm{NS}$ \\
Frequency of interaction & 0.373 & 0.130 & 0.74 & 1.04 \\
Network density & 2.162 & 0.456 & 5.51 & $0.000^{* * *}$ \\
Access to market information & 0.212 & 0.323 & 0.51 & $0.000^{* * *}$ \\
Level of education & 0.178 & 0.193 & $0.614 \mathrm{NS}$ \\
Experience in tomato business & 0.097 & & 0.51 \\
\hline
\end{tabular}

$\mathrm{N}=242, \mathrm{~F}=519.826 * * * \mathrm{R}$-squared $=0.952$, Root $\mathrm{MSE}=1.143, \mathrm{P}<0.0000$

$* * *$ Significant at $\mathrm{P}<0.01$, **Significant at $\mathrm{P}<0.05, \mathrm{NS}=$ Non Significant

The results in Table 3 show that membership in socioeconomic groups had significant positive $(\mathrm{P}<0.01)$ influence on the sales volume. This finding suggests that group membership aids access to new ideas, information and resources for business performance through social interactions and linkages within the group. The finding that membership in socio-economic groups influence performance is in line with those of Grootaert (2001) who found that membership in socio-economic groups has a positive impact on performance. The results also support findings of Ramirez (2013) who found that Knowledge among farmers comes from different social settings. Each of these sub-groups access different pools of knowledge and this knowledge is transferred between subgroups by farmers who are linked with more than one sub-group. However, these findings contradict those of Nagarajan et al., (1999) who found that membership in socio-economic groups had no influence on performance. They argued that membership in socio-economic groups reduced information problems and ensured that members had common interest.

As hypothesized network size had significant $(\mathrm{p}<0.01)$ positive influence on the sales volume. The positive coefficient suggests that better connected farmers and traders perform better than those who are less connected. This finding concurs with the finding by Fafchamps (2004) who found that better connected traders handled significantly larger sales volume than less connected traders. However, Bhaghavatula (2009) did not find positive relationship between network size and performance

The results in Table 3 further indicate that frequency of interaction among chain actors also positively influence performance $(\mathrm{P}<0.05)$. This suggest that actors who interact more frequently perform better. This is probably because actors who regularly meet each other acquire up to date market information on prices, market demand and better marketing strategies leading to higher sales volume. This finding support that of Wambugu et al, (2010) who found that frequency of attendance to meetings by group members positively influences the performance of smallholder farmer organizations. As hypothesized network density significantly $(\mathrm{P}<0.01)$ and positively influenced sales volume. This suggests that actors with high dense networks performed better than those with low dense networks. Probably it was because the former benefited from diverse and complementary ideas embodied in the network density. In addition probably it was because of repeated exchange which provided the opportunity for social relationships to grow and thereby enhance good performance. Level of education had positive influence on performance $(\mathrm{P}<0.01)$. This suggests that better educated actors performed better than those with low education. This is probably because education level enhances actors to perceive an opportunity based on an individual's knowledge and having an entrepreneurial propensity. There are some indications that level of education is an important resource for gaining competitive advantage and consequently led to higher sales volume. These results support the findings by Habar and Reichel (2007) and Segal et al (2009) who found that being better educated led to higher firm performance in terms of market share, sales revenue, sales volume growth, net worth and profitability.

\subsection{Social Networks and Gross Margin}

Table 4 shows that only network size and network 
density had significant influence on gross margin per tenga. As hypothesized network size significantly and positively $(\mathrm{P}<0.01)$ influenced actor's gross margin. Probably it was due to regular contacts with clients which reduced search costs. The positive and significant $(\mathrm{p}<0.05)$ influence of network density on actor's gross margin might probably be due to high degree of trustworthiness among members which in turn reduced search and market information acquisition costs. However, the finding is contrary to the finding by Batjargal (2003) who found that network density had no impact on firm's performance

Table 4: Regression results of the variables that influence gross margin

\begin{tabular}{lllll}
\hline Variables $(\boldsymbol{\alpha})$ & Coefficient & Std. error & T-value & Significance level \\
\hline Membership in socio-economic groups & 552.349 & 570.916 & 0.97 & $0.334 \mathrm{NS}$ \\
Network type & 821.881 & 354.915 & 1.49 & $0.139 \mathrm{NS}$ \\
Network size & 197.339 & 47.028 & 4.20 & $0.000^{* * *}$ \\
Duration in relationship & 58.317 & 685.887 & 0.09 & $0.932 \mathrm{NS}$ \\
Frequency of interaction & 562.642 & 570.359 & 0.99 & $0.325 \mathrm{NS}$ \\
Network density & 4166.406 & 1726.657 & 2.41 & $0.017^{* *}$ \\
Access to market information & -366.641 & 770.144 & -0.48 & $0.634 \mathrm{NS}$ \\
Level of education & 174.44 & 122.595 & 1.42 & $0.156 \mathrm{NS}$ \\
Experience in tomato business & -2.451 & 731.364 & -0.00 & $0.997 \mathrm{NS}$ \\
\hline
\end{tabular}

$\mathrm{N}=242, \mathrm{~F}=68.876^{* * *} \mathrm{R}$-squared $=0.726$, Root MSE, 4331.3, $\mathrm{P}<0.0000$

*** Significant at $\mathrm{P}<0.01$, ** Significant at $\mathrm{P}<0.05$, NS $=$ Non- Significant

The results in Tables 3 and 4 suggest acceptance of hypothesis that social networks have significant positive influence on performance of the fresh tomato supply chain. While the results in Table 3 suggest membership in socio-economic groups, network size, frequency of interaction and network density had positive influence on actor's sales volume. The results in Table 4 suggest that network size and network density had positive influence on actor's gross margin.

\section{Conclusions and Recommendations}

The objective of this study was to determine the effect of social networks on performance of the fresh tomato supply chain. To address this objective it was hypothesized that social networks have positive influence on performance of the fresh tomato supply chain. Results from the multiple regression analyses revealed that membership in socio-economic groups, network size, tie strength and network density have positively influence on the sales volume. On the other hand, results from the second regression analysis revealed that network size and network density have positive influence on the gross margin. Based on the multiple regression analyses it is be concluded that social networks have significant positive influence on performance of the fresh tomato supply chain in the study area.

It is recommended that the government should recognize the importance of informal social networks and strengthen the existing social networks. It should also enhance supply chain activities and reduce constraints by increasing funding for physical infrastructure and improve access to market information and capital for the farming and marketing activities.

\section{References}

[1] Aldrich, HE. \& Zimmer, C. (1986). Entrepreneurship through social networks In Sexton, D. L. \& Smilor, R. W. (Ed.). The Art and Science of Entrepreneurship 6(2): 3-23.
[2] Anggraeni, L. (2009). The function of social networks to credit access and off-farm work: a case of coconut farmers in rural areas of Riau province Indonesia. Journal of ISSAAS 15 (7): 63 76.

[3] Bryman, A. (2012). Social Research Methods. New York, Oxford University Press.

[4] Bhagavatula, S. (2009). Weaving Social Networks: Performance of small rural firms in India as an outcome of entrepreneur/s social and human capital". PhD Thesis, VU University, The Netherlands.

[5] Batjargal, B. (2003). Social capital and entrepreneurial performance in Russia: A longitudinal study. Organization Studies 24:535-556.

[6] Burt, R. S. (1992). Structural Holes: The social structure of Competition". Harvard University Press: Cambridge, Massachusetts.

[7] Burt, R. S. (2000). The network structure of social capital. In Sutton, R. I., Staw, B. M. (Eds), Networks and Organizations, JAI Press, Greenwich.

[8] Clark, L. (2006). Building Farmers' Capacities for Networking: Strengthening agricultural supply chains in Bolivia using network analysis. KM4D Journal 2:19-32.

[9] Eaton, D. Meijerink, G. Bijman, J. \& Belt, J. (2007). Analysis of the Role of Institutional Arrangements: Vegetable Value Chains in East Africa, In 106th Seminar of the EAAE, 25 - 27 October Montpellier, France.

[10] Fafchamps, M. (1996). The enforcement of commercial contracts in Ghana. World Development 24: 427-448.

[11] Fafchamps, M. (2004). Market Institutions in Sub-Saharan Africa. Cambridge, MA: MIT Press.

[12] Fukuyama, F. (2001). Social Capital, Civil Society and Development, Third World Quarterly 22:7-21.

[13] Grootaert, C. (2001). Does social capital help the poor? A synthesis of findings from the local level institutions studies in Bolivia, Burkina Faso, and Indonesia, Local Level Institutions Working Paper No. 10, World Bank, Social Development Department, Washington D. C. 
[14] Habar, S, \& Reichel, A. (2007). The cumulative nature of the entrepreneurial process: The contribution of human capital, planning and environmental resources to small venture performance. Journal of Business Venturing 22 (1): 119-145.

[15] Hualiang, I. Trienekens H. Omta, S. \& Shuyi, F. (2009). The Role of Guanxi Networks in Vegetable Supply Chains: Journal of International Food and Agribusiness Marketing 21:98-115.

[16] Jessen, J. \& Greve, A. (2002). Does the degree of redundancy in social networks influence the success of business start-ups? International Journal of Entrepreneurial Behavior and Research 8(5): 254-267.

[17] Koenig, T. Blatt, J. Brakel, K. Kloss, K. Nilges, T. \& Woellert, F. (2008). Market -driven development and poverty reduction: A value chain analysis of fresh vegetables in Kenya and Tanzania.

[18] Match Maker Associates (MMA). (2008). Fresh and processed tomatoes for local and regional markets Sub Sector Quick Scan, Tanzania. SME competitiveness facility.

[19] Mwagike, L. and Mdoe, N. (2015). The Role of Middlemen in Fresh Tomato Supply Chain in Kilolo District, Tanzania. International Journal of Agricultural Marketing 2(3):045-056.

[20] Ramirez, A. (2013). The Influence of Social Networks on Agricultural Technology Adoption. Social and Behavioral Sciences 79: $101-116$.
[21] Peng, M. \& Luo, Y. (2000). Managerial ties and firm performance in a transition economy: The nature of a micromacro link. Academy of Management Journal 43(3): 486-501.

[22] Segal, G. Borgia, D. \& Schoenfeld, P. (2009). Founder human capital and small firm performance: An empirical study on founder managed natural foods stores: Journal of Management and Marketing Research. 34(5): 1-10.

[23] United Republic of Tanzania (URT). (2012). National Sample Census of Agriculture for 2007/2008: Regional Report: Iringa Region, Volume Vk Tanzania.

[24] Wambugu, SN. Okello, JJ. \& Nyika, RA. (2010). Effect of Social Capital on Performance of Smallholder Farmer Organizations in Western Kenya. Journal of Agricultural Science and Technology 4 (6):1-19.

[25] Watson, J. (2007). Modeling the relationship between networking and firm performance. Journal of Business Venturing 22: 852-874.

[26] Zuwarimwe, J. \& Kirsten, J. (2011). Social networks and rural non-farm enterprise development and implication for poverty reduction among rural households in Zimbabwe. International Research Journals 2(3):1031-1042. 